\title{
Composição centesimal e mineral de plantas medicinais comercializadas no mercado do Porto de Cuiabá, Mato Grosso, Brasil
}

\author{
PEDRO, F.G.G.'; ARRUDA, G.L.1; OLIVEIRA, J.C.1; SANTOS, A.D.1; SIGARINI, K.S.1; HERNANDES, T.2; \\ VILLA, R.D.2; OLIVEIRA, A.P. ${ }^{*}$ \\ 1 Instituto Federal de Educação, Ciência e Tecnologia de Mato Grosso, Campus Cuiabá - Bela, Vista, Av. Juliano \\ Costa Marques, s/n - Cuiabá-MT, CEP: 78050-560. 'niversidade Federal de Mato Grosso, Campus Cuiabá, \\ Av. Fernando Corrêa da Costa, $n^{\circ}$ 2367- Cuiabá - MT, CEP: 78060-900. *Autor para correspondência: adriana. \\ oliveira@blv.ifmt.edu.br
}

\begin{abstract}
RESUMO: O presente trabalho teve como objetivo determinar a composição centesimal (cinzas, umidade, proteínas, lipídeos e carboidratos totais) e mineral ( $\mathrm{Na}, \mathrm{K}, \mathrm{Ca}, \mathrm{Cu}, \mathrm{Fe}, \mathrm{Mg}$, $\mathrm{Mn}$ e $\mathrm{Zn}$ ) das plantas medicinais Barbatimão (Stryphnodendron adstringens (Mart.) Coville), Carqueja (Baccharis trimera (Less) D.C.), Mangava-Brava (Lafoensia pacari A. St.-Hil.), e Quebra Pedra (Phyllanthus niruri L.) comercializadas no mercado do Porto de Cuiabá, MT. As amostras foram identificadas botanicamente por meio da exsicata feita no Instituto de Botânica da Universidade Federal de Mato Grosso, Campus Cuiabá. A composição centesimal foi determinada de acordo com as recomendações da Association of Official Analytical Chemists e a concentração dos minerais foi quantificada por Espectrometria de Absorção Atômica em Chama. Os resultados obtidos foram: umidade $(7,72 \%$ a $12,10 \%)$; cinzas $(1,64 \%$ a $8,44 \%)$; proteínas $(2,36 \%$ a $9,35 \%)$; lipídeos $(0,41 \%$ a $2,05 \%)$; carboidratos totais $(72,09 \%$ a $82,37 \%)$ $e$, foram encontradas diferenças significativas entre as amostras $(p<0,05)$. As concentrações dos minerais nas amostras variaram de 0,01 a $21,57 \mathrm{mg} / \mathrm{g}$ nas plantas secas e 0,01 a 32,17 $\mathrm{mg} / 200 \mathrm{~mL}$ das infusões. Os resultados médios obtidos indicam que, exceto para o K, Ca e Mn todas as amostras não apresentaram diferenças significativas $(p \geq 0,05)$ nas concentrações de minerais. A capacidade de extração dos minerais da matéria seca para a infusão obedeceu à seguinte ordem: $\mathrm{Na}>\mathrm{K}>\mathrm{Zn}>\mathrm{Cu}>\mathrm{Mg}>\mathrm{Mn}>\mathrm{Ca}>\mathrm{Fe}$. Os valores obtidos em $200 \mathrm{~mL}$ das infusões quando comparados aos índices diários recomendados para minerais sugerem que os chás avaliados podem ser fonte de minerais, principalmente de $\mathrm{K}$ e Mn.
\end{abstract}

Palavras-chave: Plantas medicinais, metais, composição proximal, infusão.

\begin{abstract}
Centesimal and mineral composition of medicinal plants commercialized in the Cuiabá Port Market, Mato Grosso, Brazil. The purpose of this study was to determine the proximal (ash, moisture, protein, lipids, and total carbohydrates) and mineral ( $\mathrm{Na}, \mathrm{K}, \mathrm{Ca}$, $\mathrm{Cu}, \mathrm{Fe}, \mathrm{Mg}, \mathrm{Mn}$, and $\mathrm{Zn}$ ) composition of the medicinal plants barbatimão (Stryphnodendron adstringens (Mart.) Coville), carqueja (Baccharis trimera (Less) D.C.), mangava-brava (Lafoensia pacari A. St.-Hil.), pau-tenente (Quassia amara L.), and quebra pedra (Phyllanthus niruri L.), commercialized in the Cuiabá Port Market in Mato Grosso. The samples were botanically identified by the voucher specimen grown in the Botanical Institute of the Federal University of Mato Grosso, at the Cuiabá campus. Proximal composition was determined according to the recommendations of the Association of Official Analytical Chemists and the concentration of minerals was quantified by flame atomic absorption spectrometry. The results obtained were: moisture content $(7.72 \%$ to $12.10 \%)$; ashes $(1.64 \%$ to $8.44 \%)$; protein $(2.36 \%$ to $9.35 \%)$; lipids $(0.41 \%$ to $2.05 \%)$, and total carbohydrates $(72.09 \%$ to $82.37 \%)$, and significant differences were found between the samples ( $p \geq 0.05)$. The mineral concentrations varied from 0.01 to $21.57 \mathrm{mg} / \mathrm{g}$ in the plants and 0.01 to $32.17 \mathrm{mg} / 200 \mathrm{~mL}$ in the infusions. No significant differences $(p \geq 0.05)$ were found between the samples for mineral composition, except for $\mathrm{K}, \mathrm{Ca}$, and $\mathrm{Mg}$. The mineral extraction capacity of the dry matter for infusions was as follows: $\mathrm{Na}>\mathrm{K}>\mathrm{Zn}>\mathrm{Cu}>\mathrm{Mg}>\mathrm{Mn}>\mathrm{Ca}>\mathrm{Fe}$. The daily index values of the metal species quantified in $200 \mathrm{~mL}$ infusions suggest that teas can be a source of minerals, especially $\mathrm{K}$ and $\mathrm{Mn}$.
\end{abstract}

Keywords: Medicinal plants, metals, proximal composition, infusion. 


\section{INTRODUÇÃO}

Chá medicinal é definido como uma bebida obtida da infusão ou cocção de folhas, cascas ou raízes na forma seca ou in natura de um vegetal que contém substâncias ou classes de substâncias responsáveis por ação terapêutica.

Os chás medicinais são consumidos no Brasil principalmente para cura e prevenção de doenças. Segundo Teixeira et al. (2014) aproximadamente $80 \%$ da população dos países em desenvolvimento utilizam algum tipo de medicina tradicional e dentre essas, se encontra o consumo de chás medicinais.

O Barbatimão (Stryphnodendron adstringens (Mart.) Coville) é uma planta do cerrado de 4 - 5 m de comprimento, caule grosso e tortuoso, copa alongada, pertencente à família Mimosoideae. Sua casca é usada na medicina popular como antiinflamatório, cicatrizante e para cura de úlcera. Essa planta contém em sua composição grande quantidade de taninos, o que estimula o aumento do extrativismo, ameaçando a espécie (Carlos et al., 2013; Goulart et al., 2012; Teixeira \& Martins, 2009).

A Carqueja (Baccharis trimera (Less) D.C.) planta da família Asteraceae, é um arbusto ereto, ramificado na base, com altura entre 0,5 e 4,0 metros, folhas dispostas ao longo do caule, ramos como expansões aladas e inflorescências dispostas lateralmente nos ramos, de cor esbranquiçada. Os compostos mais conhecidos na carqueja são terpenos, carquejol, derivados de clerodane, saponinas e glicosídeos. A espécie é comum na região Sul do Brasil, apresentando propriedades digestivas, antiácida, analgésica, anti-inflamatória, antioxidante, antimicrobiana, inseticida. É recomenda para tratamento de úlcera, malária, diabetes, diarreias, obesidade, hipertensão arterial, disfunções estomacais e intestinais (Amaral et al., 2010; Borges et al., 2007; Figueiredo \& Pereira , 2009; Karam et al., 2013).

A Mangava-brava (Lafoensia pacari A. St.- Hil.) pertencente à família Lythraceae é uma espécie peculiar do cerrado, mata ciliar e florestas de altitude. Pode medir de 3 a 30m de altura, as flores apresentam-se ligeiramente inclinadas acima da copa, possuem coloração branca-amarelada e libera odor desagradável. O fruto tem forma de cápsula conspícua e sementes aladas. O caule possui casca lisa de pequena espessura e cor marromamarelada. Sendo esse a parte da planta mais ingerida pela população. É utilizado na medicina popular para tratamento contra obesidade, irritações na pele e moléstias no estômago, atuando com efeitos cicatrizante, antifúngico, anti-inflamatório e bactericida (Cabral \& Pasa, 2009; Santos et al., 2009).

O Phyllanthus niruri L. pertence a família das Phyllanthaceae é conhecida popularmente como quebra pedra. Têm sido utilizada pela população no tratamento de moléstias no sistema urinário, doença inflamatória do intestino, diabetes, hepatite e problemas nos ovários. Natural das regiões tropicais e subtropicais do Brasil é uma erva daninha encontrada em ambientes úmidos. Apresenta folhas opostas e simples, base atenuada e frutos do tipo cápsula tricoca com aproximadamente $1 \mathrm{~mm}$ de diâmetro. Contém em sua composição lignanas, alcalóides, fenóis, ácido gálico e flavonóides (Aita et al., 2009; Silva et al., 2012; Victório et al., 2010).

Os chás medicinais em sua maioria são consumidos de forma oral e, o estudo da composição centesimal e mineral destes vem merecendo destaque nas últimas décadas a fim de garantir a importância do ponto de vista nutricional e os efeitos benéficos à saúde humana (Hussain et al., 2009).

Vários trabalhos na literatura têm descrito a composição centesimal e mineral de plantas medicinais utilizadas na forma de chás em diversos países (Marbaniang et al., 2011; Randelović et al., 2013; Lahiji et al., 2013) e no Brasil (Garbin et al., 2013; Amarante et al., 2011; Marques et al., 2012).

Os minerais essenciais têm um papel vital no funcionamento do organismo humano. Eles participam de diversos processos metabólicos e atuam em reações bioquímicas e aparecem como ativadores ou componentes de algumas enzimas específicas (Król et al., 2012). Como exemplo, o sódio, potássio, cálcio e magnésio auxiliam na contração muscular. O potássio associado ao sódio regula o sistema muscular e os batimentos cardíacos, contribuem para controle da pressão osmótica, água e equilíbrio ácido-base. Além disso, o potássio participa da síntese de proteínas e formação de glicogênio. O cálcio e o magnésio atuam na formação de ossos, dentes e possuem papel importante na ativação de enzimas. O ferro é elemento traço de maior importância e abundância no organismo humano, participante na formação de hemoglobina e mioglobina, desempenhando um papel essencial no transporte de oxigênio e respiração celular. $O$ zinco e o manganês são ativadores importantes de reações catalisadas por enzimas, desempenhado papel importante para a reprodução e crescimento de um indivíduo. $O$ cobre atua como componente de inúmeras enzimas participantes do processo de produção de energia, na formação de tecidos conjuntivos e na produção de melanina, além de ser um ótimo antioxidante (Almeida et al., 2002; Fiorini, 2008; Zhang et al., 2014).

Tendo em vista, fornecer subsídios para o controle de qualidade da matéria-prima e também

Rev. Bras. PI. Med., Campinas, v.18, n.1, supl. I, p.297-306, 2016. 
informações sobre o conteúdo nutricional de plantas medicinais amplamente consumidas com propósito terapêutico pela população, o presente trabalho teve como objetivo determinar a composição mineral ( $\mathrm{Na}, \mathrm{K}, \mathrm{Ca}, \mathrm{Cu}, \mathrm{Fe}, \mathrm{Mg}, \mathrm{Mn}$ e Zn) e a composição centesimal (umidade, cinzas, proteínas, lipídeos e carboidratos totais) das plantas medicinais Barbatimão (Stryphnodendron adstringens (Mart.)), Carqueja (Baccharis trimera), Mangava-Brava (Lafoensia pacari A. St.-Hil.) e Quebra Pedra (Phyllanthus niruri L.) comercializadas no mercado do Porto, localizado na cidade de Cuiabá, MT.

\section{MATERIAL E MÉTODOS Material Instrumentação}

Para a quantificação dos minerais foi utilizado um espectrômetro de absorção atômica em chama modelo SpectrAA 220 com corretor de fundo do tipo lâmpada de deutério e lâmpadas de cátodo oco ambos da marca Varian ${ }^{\circledast}$. Acetileno (99,5 \%, Linde Gás, São Paulo, Brasil) e ar comprimido foram utilizados como gases combustível e oxidante para a determinação de $\mathrm{Na}, \mathrm{K}, \mathrm{Mg}, \mathrm{Fe}, \mathrm{Cu}, \mathrm{Zn}$ e Mn. Para o elemento Ca foram utilizados os gases acetileno e óxido nitroso (99,5\%, Linde Gás, São Paulo, Brasil) como combustível e oxidante, respectivamente. As taxas de aspiração das soluções padrão de calibração e amostras foram ajustadas em 2,00 \pm $0,2 \mathrm{~mL} \mathrm{~min}^{-1}$. Todas as determinações foram feitas de acordo com as recomendações do fabricante. A Tabela 1 mostra as condições instrumentais utilizadas para cada analito.

As medidas de massa foram feitas em uma balança analítica Marca Marte ${ }^{\circledR}$ Modelo AW 220 (precisão de $\pm 0,0001 \mathrm{~g}$ ). A secagem das amostras e a determinação do teor de umidade foram executadas em estufa Marca Olidef $\mathrm{Cz}^{\circledR}$ e a mineralização e calcinação das cinzas em forno mufla marca Quimis ${ }^{\circledR}$. O procedimento de preparo das infusões foi feito em uma chapa aquecedora Marca Quimisø.

A determinação do teor de proteínas foi feita em destilador de Kjedahl marca Tecnal ${ }^{\circledR}$ modelo TE0364 e, o teor de lipídios pelo Extrator de Gordura Soxhlet marca Marconi® modelo 044/850.

\section{Reagentes e soluções}

Para o preparo das soluções padrão de calibração dos minerais e das amostras foi utilizada água deionizada de alta pureza (resistividade 18,2 $\mathrm{M} \Omega \mathrm{cm}$-1) obtida em sistema deionizador da marca Millipore ${ }^{\circledR}$. As soluções padrões de calibração foram feitas por meio de diluições sucessivas de padrões espectroscópicos aquosos de concentração 1000 $\mathrm{mg} \mathrm{L}^{-1}$ (Marca SpecSol囚 AA) em meio aquoso. Para a diluição da amostra mineralizada em meio aquoso foi utilizado $\mathrm{HCl}$ concentrado ( PAACS $37 \%$, Marca MT Labor) Na determinação de proteínas foi utilizado, $\mathrm{H}_{2} \mathrm{SO}_{4}$ concentrado (PA ACS $95-98 \%$, Marca Quemis) e uma mistura de catalisadores $\left(96 \% \mathrm{~K}_{2} \mathrm{SO}_{4}, 4 \% \mathrm{CuSO}_{4} \cdot 5 \mathrm{H}_{2} \mathrm{O}\right.$, Mar ca Quemis). Para a digestão da amostra, uma solução de $\mathrm{NaOH}$ (PA 97\%, Marca Nova Ética) a 60\% (m:v) foi utilizada para transformação do nitrogênio da proteína em sulfato de amônio, solução de ácido bórico (PAACS 99,5\%, Marca Quemis) a 2\% (m:v) como solução coletora e solução padronizada de $\mathrm{HCl}$ ( PA ACS 37\%, Marca MT Labor) a 0,02 mol $\mathrm{L}^{-1}$, vermelho de metila (PA ACS, Marca Avantor) e verde de bromocresol (PA ACS, Marca Synth) como indicadores químicos para titular a solução resultante da destilação.

Para a determinação de lipídios foi utilizado como solvente extrator éter de petróleo (PAACS 30$60+/-2^{\circ} \mathrm{C}$, Marcas MT Labor e Qhemis).

\section{Amostras}

Quatro tipos de plantas medicinais desidratadas mais comercializadas no Mercado do Porto de Cuiabá foram adquiridas em uma banca

TABELA 1. Condições instrumentais de operação utilizadas para a determinação da composição mineral.

\begin{tabular}{lccccc}
\hline Analito & $\begin{array}{c}\text { Comprimento de } \\
\text { onda }(\mathbf{n m})\end{array}$ & $\begin{array}{c}\text { Corrente } \\
(\mathbf{m A})\end{array}$ & $\begin{array}{c}\text { Resolução } \\
\text { espectral }(\mathbf{n m})\end{array}$ & $\begin{array}{c}\text { Gases Combustível// } \\
\text { Oxidante }\end{array}$ & $\begin{array}{c}\text { Estequiometria da } \\
\text { chama }\end{array}$ \\
\hline $\mathbf{N a}$ & 330,0 & 5,0 & 0,5 & Acetileno/Ar & Oxidante \\
$\mathbf{K}$ & 769,9 & 6,0 & 1,0 & Acetileno/Ar & Oxidante \\
$\mathbf{C a}$ & 422,7 & 10,0 & 0,5 & Acetileno/Óxido Nitroso & Redutora \\
$\mathbf{M g}$ & 202,6 & 5,0 & 1,0 & Acetileno/Ar & Oxidante \\
$\mathbf{F e}$ & 272,0 & 5,0 & 1,0 & Acetileno/Ar & Oxidante \\
$\mathbf{M n}$ & 279,5 & 5,0 & 0,2 & Acetileno/Ar & Oxidante \\
$\mathbf{Z n}$ & 213,9 & 5,0 & 1,0 & Acetileno/Ar & Oxidante \\
$\mathbf{C u}$ & 327,4 & 10 & 0,2 & Acetileno/Ar & Oxidante \\
\hline
\end{tabular}

Rev. Bras. PI. Med., Campinas, v.18, n.1, supl. I, p.297-306, 2016. 
de ervas medicinais e temperos: Barbatimão (Stryphnodendron adstringens (Mart.) Coville), Carqueja (Baccharis trimera (Less) D.C.), MangavaBrava (Lafoensia pacari A. St.-Hil.) e Quebra Pedra (Phyllanthus niruri L.).

A fim de garantir a representatividade das plantas medicinais, as amostras foram adquiridas ( $250 \mathrm{~g}$ em cada coleta) em três períodos de tempo, nos meses de fevereiro, junho e outubro de 2014 e, acondicionadas em recipientes de polietileno e identificadas por numeração.

As partes das plantas utilizadas nas análises foram: cascas do barbatimão, folhas e hastes da carqueja, cascas da mangava brava e planta inteira do quebra pedra. As diferentes partes das plantas foram utilizadas nas determinações devido a estas serem as mais utilizadas na preparação dos chás com finalidades terapêuticas.

As amostras foram identificadas botanicamente por meio da exsicata feita no Instituto de Botânica da Universidade Federal de Mato Grosso, Campus Cuiabá pelo funcionário do Herbário Central da UFMT, especialista José Edivaldo da Silva.

As amostras brutas foram quarteadas e, em seguida, as amostras laboratoriais foram trituradas em liquidificador industrial e, acondicionadas em recipientes de polietileno e identificadas por numeração.

\section{MÉTODOS}

\section{Composição centesimal}

O teor de cinzas foi determinado por meio do resíduo de incineração obtido por aquecimento em forno mufla em temperatura de $550^{\circ} \mathrm{C}$, e a umidade pelo método gravimétrico por meio da secagem em estufa a $100^{\circ} \mathrm{C}$ à pressão atmosférica. O teor de proteínas foi determinado por meio do método de Kjeldahl modificado. O teor de lipídeos foi feito pelo método gravimétrico com extração em Soxhlet. Todas as determinações foram feitas em triplicata, segundo as recomendações da Official Association of Analytical Chemists (AOAC) e do Instituto Adolfo Lutz (IAL) (AOAC, 2012; Instituto Adolfo Lutz, 2008). O teor de carboidratos foi obtido por diferença [Carboidratos $=100-$ (proteínas + cinzas + umidade + lipídeos) ] segundo a Resolução RDC n³60, de 23 de Dezembro de 2003 (Brasil, 2003).

Os resultados médios da composição centesimal foram expressos em porcentagem (\%) da planta (matéria seca) e, a fim de verificar a existência de diferenças significativas entre os resultados médios obtidos foi feito o teste de Tukey $(p=0,05)$ utilizando o programa ASSISTAT ${ }^{\circledR}$ versão beta 7.7 .

\section{Composição mineral \\ Procedimento de preparo de amostras}

O procedimento de mineralização ou decomposição por via seca das plantas consistiu inicialmente da secagem das amostras laboratoriais em estufa numa temperatura de $110^{\circ} \mathrm{C}$ por 2 horas. Em seguida, as amostras foram trituradas por meio de almofariz, pistilo e liquidificador. Posteriormente, $5 \mathrm{~g}$ de amostra foram pesadas em cadinhos de porcelana pré-tratados (os cadinhos foram aquecidos por 30 minutos em formo mufla em temperatura de $580{ }^{\circ} \mathrm{C}$ ). Após pesagem, as amostras foram encaminhadas para calcinação em forno mufla o qual a temperatura foi elevada gradativamente a cada 30 minutos em $100^{\circ} \mathrm{C}$ até a temperatura de $580^{\circ} \mathrm{C}$, permanecendo assim por 14 horas para digestão completa da matéria orgânica. As cinzas foram retiradas da mufla, transferidas para dessecador, esfriadas até temperatura ambiente, Após essa etapa as amostras calcinadas foram filtradas e diluídas em solução de 1:1 (v:v) de $\mathrm{HCl}$, e transferidas quantitativamente para balão volumétrico de $50 \mathrm{~mL}$ (Almeida et al, 2002; AOAC, 2012). Todas as amostras calcinadas foram feitas triplicatas e acompanhadas de branco analítico.

O processo de infusão consistiu na pesagem de $10 \mathrm{~g}$ das amostras laboratoriais em béqueres de $250 \mathrm{~mL}$. Em seguida, $50 \mathrm{~mL}$ de água deionizada fervente foram transferidos para os béqueres que continham as plantas. As infusões foram tampadas com vidro de relógio até atingir a temperatura ambiente, e posteriormente foram transferidas para balão volumétrico de $100 \mathrm{~mL}$ (Almeida et al, 2002; AOAC, 2012). Todas as infusões foram feitas em triplicata, acompanhadas de branco analítico e analisadas no mesmo dia.

\section{minerais \\ Determinação da concentração dos}

Curvas de calibração foram feitas utilizando o método da padronização externa em diferentes faixas crescentes de concentração para cada analito a partir de diluições sucessivas de padrões espectroscópicos aquosos $1000 \mathrm{mg} \mathrm{L}^{-1} \mathrm{em}$ meio aquoso. As concentrações das curvas foram: 0,0 a $15 \mathrm{mg} / \mathrm{L}$ para o $\mathrm{Na}, 0,0$ a 5,0 mg/L para o K, Ca e Fe e 0,0 a 2,0 mg/L para o Cu, Mn, Mg e Zn. Estas curvas foram utilizadas para a obtenção dos parâmetros instrumentais e na determinação da concentração dos minerais nas amostras previamente preparadas pelos dois tipos de tratamentos descritos no item anterior. Todas as leituras foram feitas em triplicata e acompanhadas de um branco analítico.

Os limites de detecção (LDI) e de quantificação (LQI) instrumentais foram calculados de acordo com o trabalho descrito por Currie (1999) e, o coeficiente de correlação linear ( $r$ ) foi obtido por

Rev. Bras. PI. Med., Campinas, v.18, n.1, supl. I, p.297-306, 2016. 
meio da regressão linear da curva analítica (Skoog, 2009). A precisão instrumental foi determinada pelo cálculo do desvio padrão de dez leituras consecutivas das amostras.

Os resultados médios da composição mineral foram expressos em $\mathrm{mg} \mathrm{g}^{-1}$ da planta (matéria seca) e, em mg/200mL de infusão da planta.

Os valores encontrados na determinação da concentração dos minerais nas amostras foram comparados com a Resolução RDC n' 269 de 2005 (Brasil, 2005) da Agência Nacional de Vigilância Sanitária e, com a Recommended Dietary Allowances e, o Tolerable Upper Intake Level (UL) da Food and Nutrition Board, Institute of Medicine, National Academies (Food and Nutrition Board, 1998),.

Para verificar a existência de diferenças significativas entre as amostras com relação à concentração (valor médio) de cada um dos minerais foi feito o teste de Tukey $(p=0,05)$ utilizando $o$ programa ASSISTAT ${ }^{\circledR}$ versão beta 7.7 .

\section{RESULTADOS E DISCUSSÃO}

As exsicatas identificadas e ratificadas foram depositadas no Herbário do Instituto de Botânica da UFMT e arquivadas através dos números 63 (Barbatimão), 682 (Carqueja), 58 (Mangava brava) e 74 (Quebra pedra).

Os resultados obtidos na determinação da composição centesimal das plantas medicinais analisadas estão descritos na Tabela 2.

Todas as amostras apresentaram diferenças significativas em relação ao teor de umidade $(p<$ $0,05)$. As ervas barbatimão, carqueja e quebra pedra apresentaram teores de umidade de $12,10 \%$, $7,72 \%$ e 9,53\% respectivamente e, estão de acordo com os valores máximos descritos na Farmacopéia
Brasileira (Brasil, 2010) de 14\% para o barbatimão, $12 \%$ para a carqueja e $10 \%$ para o quebra pedra, indicando que estas ervas estão em condições adequadas para o controle de microrganismos e possível degradação química causadas pelo excesso de umidade (Silva et al., 2013).

Os teores de cinzas quantificados variaram de $1,64 \%$ a $8,44 \%$ e, apenas as amostras de barbatimão e carqueja apresentaram diferenças significativas $(p<0,05)$ em relação as demais amostras, sendo que o barbatimão foi o que apresentou menor teor de cinzas, enquanto a carqueja o maior valor.

Almeida et al. (2003), determinaram os teores de cinzas de dez diferentes tipos de plantas medicinais, dentre elas o quebra pedra que apresentou teor de cinzas de 6,44\%, valor próximo ao apresentado neste trabalho. Simão (2013) determinou os teores de cinzas de seis plantas medicinais utilizadas para o tratamento de obesidade, dentre elas a carqueja, e o valor encontrado para esta erva foi de 6,18 $\pm 0,05 \%$. De acordo com Almeida et al. (2003), teores de cinzas elevados (5 a 10\%) indicam a abundância de elementos minerais em plantas, o que pode ser observado neste estudo para a carqueja, mangava brava e quebra pedra.

Os teores de cinzas das plantas barbatimão, carqueja e quebra pedra estão de acordo com os valores máximos de cinzas totais referenciados na Farmacopeia Brasileira (Brasil, 2010) que são de $2 \%, 8 \%$ e $6 \%$, respectivamente. Vale salientar que a Farmacopéia Brasileira não descreve monografias para a planta medicinal mangava brava impossibilitando uma comparação específica dos teores de umidade e cinzas totais dessa erva.

Os teores de proteínas encontrados para o barbatimão e mangava brava apresentaram

TABELA 2. Resultados obtidos (valor médio \pm desvio padrão) na determinação da composição centesimal das plantas medicinais.

\begin{tabular}{lccccc}
\hline \multicolumn{1}{c}{$\begin{array}{c}\text { Amostras } \\
\text { Tratamento }\end{array}$} & Umidade & Cinzas & Proteínas & Lipídios & $\begin{array}{c}\text { Carboidratos } \\
\text { Totais }\end{array}$ \\
\cline { 2 - 5 } & & & $\%$ & \\
\hline $\begin{array}{l}\text { Barbatimão } \\
\text { (casca) }\end{array}$ & $12,10 \pm 1,03^{\mathrm{a}}$ & $1,64 \pm 0,1^{\mathrm{b}}$ & $5,44 \pm 0,44^{\mathrm{b}}$ & $1,01 \pm 0,22^{\mathrm{bc}}$ & $80,23 \pm 0,38^{\mathrm{a}}$ \\
$\begin{array}{l}\text { Carqueja } \\
\text { (hastes e folhas) }\end{array}$ & $7,72 \pm 0,94^{\mathrm{c}}$ & $8,44 \pm 3,6^{\mathrm{a}}$ & $8,62 \pm 0,74^{\mathrm{a}}$ & $1,69 \pm 0,37^{\mathrm{ab}}$ & $75,83 \pm 0,84^{\mathrm{ab}}$ \\
$\begin{array}{l}\text { Mangava Brava } \\
\text { (cascas) }\end{array}$ & $10,88 \pm 0,71^{\mathrm{ab}}$ & $5,39 \pm 1,23^{\mathrm{ab}}$ & $2,36 \pm 0,31^{\mathrm{b}}$ & $0,48 \pm 0,05^{\mathrm{c}}$ & $81,96 \pm 0,03^{\mathrm{a}}$ \\
$\begin{array}{l}\text { Quebra Pedra } \\
\text { (folhas, caule }\end{array}$ & $9,53 \pm 1,12^{\mathrm{abc}}$ & $5,71 \pm 0,30^{\mathrm{ab}}$ & $9,35 \pm 2,03^{\mathrm{a}}$ & $2,05 \pm 0,00^{\mathrm{a}}$ & $72,09 \pm 0,77^{\mathrm{b}}$ \\
e raiz) & & & & & \\
\hline
\end{tabular}

$\mathrm{a}, \mathrm{b}, \mathrm{c}, \mathrm{ab}, \mathrm{bc}, \mathrm{abc}$ valores seguidos de letras iguais na mesma coluna significa que não existe diferença significativa entre as amostras ao nível de $5 \%$ de significância pelo teste de Tukey.

Rev. Bras. PI. Med., Campinas, v.18, n.1, supl. I, p.297-306, 2016. 
diferenças significativas $(p<0,05)$ em relação aos teores determinados na carqueja e quebra pedra, sendo que estes apresentaram os maiores teores proteicos entre as amostras analisadas. Simão (2013) encontrou teores de proteínas em amostras de carqueja com valor médio de 7,15 \pm $0,22 \%$, próximos aos quantificados neste trabalho. Segundo Kinupp \& Barros (2008), as plantas podem ser consideradas fontes de proteínas foliares (leaf proteins).

Todas as amostras apresentaram diferenças significativas $(p<0,05)$ em relação ao teor de lipídeos, exceto as amostras de mangava brava que apresentaram valores concordantes entre si. No trabalho descrito por Simão (2013), o teor de lipídeos para amostras de carqueja foi de 2,49 $\pm 0,20 \%$.

As amostras apresentaram teor de carboidratos em maior porcentagem em relação aos demais componentes, sendo que o quebra pedra e a mangava brava foram as plantas medicinais que apresentaram menor e maior quantidade, respectivamente. Dentre esses carboidratos estão presentes a celulose e hemicelulose, que são responsáveis pela rigidez e resistência dos tecidos vegetais e não são digeridos pelo trato gastrointestinal humano, valores de $50,64 \%$ desses componentes foram encontrados em plantas pesquisadas por Carvalho et al. (2010).

Os teores mínimos e máximos observados na Tabela 2 para proteínas, lipídeos e carboidratos foram semelhantes aos verificados nas ervas pesquisadas por Hussain, et al. (2009).

Os diferentes valores da composição centesimal encontrados entre as amostras podem estar relacionados a origem, variedades das ervas analisadas e as diferentes estruturas vegetais das plantas (Bertol et al., 2015).

A Tabela 3 mostra os parâmetros instrumentais obtidos para a determinação da composição mineral da matéria seca e das infusões das plantas medicinais. Para os intervalos de concentração avaliados obteve-se valores de coeficiente de correlação linear $(r)$ superiores a 0,99 indicando uma excelente correlação entre a absorbância (A) e a concentração dos analitos (mg $\left.\mathrm{L}^{-1}\right)$, atendendo as recomendações da ANVISA ( $r=$ $0,99)$ e do INMETRO ( $r>0,90)$ (Ribani et. al., 2004).

Os limites de detecção e de quantificação instrumentais permitiram a quantificação dos analitos na matéria seca e nas infusões das plantas medicinais avaliadas neste trabalho. A precisão instrumental (\%) foi de 0,07(Ca), 0,03 (Cu), 0,05 (Fe), 0,02 (Mg), 0,05 (Mn), 0,03 (Na), 0,07 (K) e 0,06 (Zn) nas amostras de matéria seca e, 0,07 (Ca), 0,00 $(\mathrm{Cu}), 0,05(\mathrm{Fe}), 0,01(\mathrm{Mg}), 0,04(\mathrm{Mn}), 0,03(\mathrm{Na}), 0,06$ (K) e 0,02 (Zn) nas infusões.

Os perfis minerais das amostras de matéria seca das plantas medicinais pesquisadas estão descritos na Tabela 4. Os resultados médios obtidos indicam que, exceto para o potássio e cálcio, todas as amostras não apresentaram diferenças significativas $(p \geq 0,05)$ em relação a concentração de minerais.

Dentre os minerais pesquisados, com exceção da mangava brava que obtive maior teor de cálcio, o potássio foi o mineral que obteve maiores concentrações nas ervas analisadas. Este fato também é observado na maioria dos trabalhos da literatura referentes a análise de minerais em plantas medicinais, visto que essa espécie metálica é a mais abundante em vegetais (Silveira et.al, 2009). Valores semelhantes aos determinados neste trabalho foram obtidos nas ervas pesquisadas por Almeida et al., 2002; Olivier, et al., 2012 e Randelović et al., 2013.

A heterogeneidade do perfil mineral das plantas, da mesma forma que a composição centesimal pode estar associada a origem, tipo de

TABELA 3. Parâmetros instrumentais.

\begin{tabular}{cccccc}
\hline Analitos & Faixa linear $\left(\mathbf{m g ~ L}^{-1}\right)$ & Curva analítica & LDI $(\mathbf{m g ~ L}-1)$ & LQI $(\mathbf{m g ~ L - 1})$ & $\mathbf{r}$ \\
\hline $\mathrm{Na}$ & $0,0-15,0$ & $\mathrm{~A}=0,0020 \mathrm{C}_{\mathrm{Na}}-0,014$ & 0,4800 & 1,4600 & 0,9976 \\
$\mathrm{~K}$ & $0,0-5,0$ & $\mathrm{~A}=0,0609 \mathrm{C}_{\mathrm{K}}-0,0518$ & 0,0160 & 0,0490 & 0,9900 \\
$\mathrm{Ca}$ & $0,0-5,0$ & $\mathrm{~A}=0,0161 \mathrm{C}_{\mathrm{Ca}}-0,0006$ & 0,0360 & 0,1100 & 0,9940 \\
$\mathrm{Cu}$ & $0,0-2,0$ & $\mathrm{~A}=0,0687 \mathrm{C}_{\mathrm{Cu}}+0,0002$ & 0,0079 & 0,0240 & 0,9998 \\
$\mathrm{Fe}$ & $0,0-5,0$ & $\mathrm{~A}=0,0342 \mathrm{C}_{\mathrm{Fe}}-0,0002$ & 0,0525 & 0,1591 & 0,9993 \\
$\mathrm{Mg}$ & $0,0-2,0$ & $\mathrm{~A}=0,5793 \mathrm{C}_{\mathrm{Mg}}+0,083$ & 0,0039 & 0,0119 & 0,9983 \\
$\mathrm{Mn}$ & $0,0-2,0$ & $\mathrm{~A}=0,0828 \mathrm{C}_{\mathrm{Mn}}+0,0002$ & 0,0081 & 0,0246 & 0,9999 \\
$\mathrm{Zn}$ & $0,0-2,0$ & $\mathrm{~A}=0,1247 \mathrm{C}_{\mathrm{Zn}}+0,0081$ & 0,0090 & 0,0272 & 0,9943 \\
\hline
\end{tabular}

A: Absorbância; C: concentração do analito em mg L-1; LDI: Limite de detecção instrumental; LQI: Limite de quantificação instrumental; r: Coeficiente de correlação linear.

Rev. Bras. PI. Med., Campinas, v.18, n.1, supl. I, p.297-306, 2016. 
TABELA 4. Concentrações médias (em $\mathrm{mg} \mathrm{g}^{-1}$ ) e os respectivos desvios padrões para $\mathrm{Na}, \mathrm{K}, \mathrm{Ca}, \mathrm{Cu}, \mathrm{Fe}, \mathrm{Mg}$, $\mathrm{Mn}$ e $\mathrm{Zn}$ nas amostras de matéria seca das plantas Barbatimão, Carqueja, Mangava Brava e Quebra-Pedra.

\begin{tabular}{|c|c|c|c|c|}
\hline \multirow[b]{2}{*}{ Minerais } & Barbatimão & Carqueja & Mangava Brava & Quebra Pedra \\
\hline & \multicolumn{4}{|c|}{$\mathbf{m g ~ g}^{-1}$} \\
\hline $\mathrm{Na}$ & $0,02 \pm 0,00^{a}$ & $0,06 \pm 0,03^{a}$ & $0,03 \pm 0,00^{a}$ & $0,05 \pm 0,01^{\text {a }}$ \\
\hline K & $3,35 \pm 2,89^{\circ}$ & $21,57 \pm 2,72^{a}$ & $1,14 \pm 0,13^{b}$ & $17,18 \pm 1,11^{a}$ \\
\hline $\mathrm{Ca}$ & $1,75 \pm 0,02^{\mathrm{d}}$ & $7,27 \pm 0,58^{\mathrm{b}}$ & $12,22 \pm 0,01^{a}$ & $4,44 \pm 0,79^{c}$ \\
\hline $\mathrm{Cu}$ & $<\mathrm{LQ}^{\circ}$ & $0,01 \pm 0,00^{a}$ & $<\mathrm{LQI}^{*}$ & $0,01 \pm 0,00^{a}$ \\
\hline $\mathrm{Fe}$ & $0,03 \pm 0,01^{a}$ & $0,27 \pm 0,24 a$ & $<\mathrm{LQ}^{*}$ & $0,10 \pm 0,00^{a}$ \\
\hline $\mathrm{Mg}$ & $2,97 \pm 1,95^{\mathrm{a}}$ & $1,66 \pm 0,30^{a}$ & $0,86 \pm 0,10^{a}$ & $1,96 \pm 0,36^{a}$ \\
\hline $\mathrm{Mn}$ & $0,01 \pm 0,00^{a}$ & $0,06 \pm 0,01^{a}$ & $0,10 \pm 0,05^{a}$ & $0,17 \pm 0,11^{a}$ \\
\hline $\mathrm{Zn}$ & $<\mathrm{LQ}^{*}$ & $0,03 \pm 0,02^{a}$ & $0,01 \pm 0,00 a$ & $0,01 \pm 0,00 a$ \\
\hline
\end{tabular}

a,b, c valores seguidos de letras iguais na mesma linha significa que não existe diferença significativa entre as amostras ao nível de $5 \%$ de significância pelo teste de Tukey; LQl' Limite de quantificação instrumental.

planta, as estruturas vegetais analisadas e também a fatores como tipo de solo e cultivo, uso de fertilizantes e agroquímicos (Bertol et al, 2015).

Os resultados médios do perfil mineral das infusões (Tabela 5) indica que, exceto para o cálcio e manganês, todas as amostras não apresentaram diferenças significativas $(p \geq 0,05)$ em relação à concentração de minerais.

Para o cálcio, as maiores concentrações foram encontradas nas infusões de quebra pedra. Já para o manganês, a infusão de quebra pedra apresentou maior concentração deste mineral em relação as demais plantas avaliadas neste estudo. Da mesma forma que na matéria seca das plantas (Tabela 3 ), o potássio foi o mineral que apresentou maior concentração nas infusões.

Os resultados obtidos no perfil mineral das infusões sugerem que a capacidade de extração dos minerais nas plantas avaliadas segue a seguinte sequência decrescente: $\mathrm{Na}>\mathrm{K}>\mathrm{Zn}>\mathrm{Mn}>\mathrm{Mg}>\mathrm{Cu}>\mathrm{Ca}>\mathrm{Fe}$. A concentração de minerais em extratos ou infusões aquosas de plantas medicinais pode ser afetada por vários fatores como: o teor de matéria orgânica presente na planta medicinal que pode atuar como agente quelante das espécies metálicas; a solubilidade do mineral e da matéria orgânica em água; energia de solvatação da espécie metálica e o $\mathrm{pH}$ da água utilizada para o preparo da infusão (Randelovic et al., 2013).

As concentrações médias dos minerais avaliados contidos numa xícara padrão $(200 \mathrm{~mL})$ apresentadas na Tabela 5 foram comparadas com os valores de referência: Recommended Dietary Allowances (RDA) que apresenta os níveis de ingestão diária recomendada de um nutriente recomendado pela Food and Nutrition Board
(FNB) para satisfazer os requisitos deindivíduos saudáveis em diferentes estágios da vida, de grupo e gênero; Tolerable Upper Intake Level (UL) denominado como limite máximo tolerável de ingestão ou o nível máximo da ingestão crônica diária total de um nutriente também estabelecido pela FNB e, os teores diários recomendados pela Resolução RDC n² 269, de 22 de setembro de 2005 da ANVISA (Food and Nutrition Board, 1998; Brasil, 2005).

Os teores extraídos dos minerais analisados da planta seca para as infusões não ultrapassaram os limites recomendados para o consumo humano, segundo os valores de referência utilizados neste trabalho.

Os minerais potássio e manganês foram os que apresentaram maior porcentagem presente em $200 \mathrm{~mL}$ de infusão em relação à ingestão diária recomendada, sendo que planta Quebra Pedra apresentou os maiores teores destes dois minerais.

Alguns trabalhos descritos na literatura indicam uma elevada concentração de manganês presente em infusões de plantas medicinais (Amarante et al., 2011). Segundo Fiorini (2008) o manganês é constituinte de diversas enzimas e atua como ativador de várias outras, dentre essas as que participam do metabolismo dos carboidratos, aminoácidos e colesterol, é antioxidante e faz parte da formação da cartilagem e ossos. Esse mineral é considerado em oligoterapia como um carro-chefe, sendo básico no tratamento da diátese alérgica. Este tratamento melhora consideravelmente as crianças ditas frágeis, frequentemente resfriadas e com problemas de fixação da atenção. Além disso, o manganês possui ainda, importantes indicações no campo da artrose. 
TABELA 5. Concentrações médias calculadas de $\mathrm{Na}, \mathrm{K}, \mathrm{Ca}, \mathrm{Cu}, \mathrm{Fe}, \mathrm{Mg}, \mathrm{Mn}$ e $\mathrm{Zn}$ em $200 \mathrm{~mL}$ das infusões de Barbatimão, Carqueja, Mangava-Brava e Quebra Pedra e os respectivos desvios padrões.

\begin{tabular}{|c|c|c|c|c|c|c|c|}
\hline \multirow{2}{*}{ Minerais } & Barbatimão & Carqueja & Mangava Brava & Quebra Pedra & RDA $^{* * *}$ & ANVISA & UL \\
\hline & & \multicolumn{3}{|c|}{$\mathrm{mg} / 200 \mathrm{~mL}$} & \multicolumn{3}{|c|}{$\mathrm{mg} / \mathrm{dia}$} \\
\hline $\mathrm{Na}$ & $0,38 \pm 0,08^{a}$ & $0,31 \pm 0,20^{a}$ & $0,40 \pm 0,06^{a}$ & $0,35 \pm 0,08^{a}$ & 1500 & - & \\
\hline $\mathrm{K}$ & $14,45 \pm 4,12^{a}$ & $V A^{* *}$ & $27,65 \pm 3,70^{a}$ & $25,32 \pm 7,07^{a}$ & 4700 & - & \\
\hline $\mathrm{Ca}$ & $1,27 \pm 0,07^{b}$ & $1,43 \pm 0,80^{\circ}$ & $0,94 \pm 0,05^{b}$ & $4,39 \pm 1,12^{a}$ & 1000 & 1000 & 2500 \\
\hline $\mathrm{Cu}$ & $<\mathrm{LQ}^{\circ}$ & $0,01 \pm 0,00$ & < LQ| & $<\mathrm{LQI}^{*}$ & 0,9 & 0,9 & 10 \\
\hline $\mathrm{Fe}$ & $<\mathrm{LQI}^{\circ}$ & $0,06 \pm 0,05$ & $<\mathrm{LQ}^{\circ}$ & $<$ LQl$^{\circ}$ & 8 н/18м & 14 & 45 \\
\hline $\mathbf{M g}$ & $1,79 \pm 0,05^{a}$ & $1,01 \pm 0,14^{a}$ & $1,68 \pm 0,20^{a}$ & VAA & $400 / 310$ & 260 & 350 \\
\hline Mn & $0,01 \pm 0,00^{b}$ & $0,10 \pm 0,04^{b}$ & $0,13 \pm 0,00^{b}$ & $0,29 \pm 0,06^{a}$ & $2,3^{\mathrm{H}} / 1,8^{\mathrm{M}}$ & 2,3 & 11 \\
\hline $\mathrm{Zn}$ & $0,03 \pm 0,01^{a}$ & $0,02 \pm 0,01^{a}$ & $<\mathrm{LQI}^{*}$ & $0,07 \pm 0,01^{a}$ & $11 / 8$ & 7 & 40 \\
\hline
\end{tabular}

a,b:valores seguidos de letras iguais na mesma coluna significa que não existe diferença significativa entre as amostras ao nível de $5 \%$ de significância pelo teste de Tukey. LQl' Limite de quantificação instrumental. VA“Valor anômalo."' Recommended Dietary Allowances para

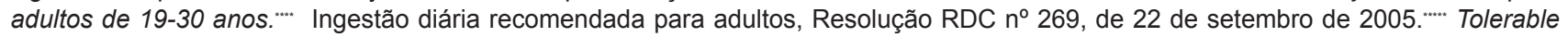
Upper Intake Level para adultos de 19-30 anos. H: homens. M: mulheres.

\section{CONCLUSÕES}

A composição centesimal das plantas medicinais avaliadas neste trabalho apresentou diferenças significativas entre as amostras e, os teores de umidade e cinzas das amostras de barbatimão, carqueja e quebra pedra estão de acordo com os valores descritos na Farmacopéia Brasileira.

Para a matéria seca das plantas medicinais, todas as amostras não apresentaram diferenças significativas $(p \geq 0,05)$ em relação à concentração de minerais, exceto os minerais potássio e cálcio. Nas infusões, apenas o cálcio e o manganês apresentaram diferenças significativas $(p<0,05)$ entre as amostras.

As diferenças encontradas na composição centesimal e ao perfil mineral pode estar associadas a origem, tipo de planta, as estruturas vegetais analisadas e também a fatores como tipo de solo e cultivo, clima, uso de fertilizantes e agroquímicos.

A capacidade de extração dos minerais da matéria seca para a infusão obedeceu a seguinte ordem: $\mathrm{Na}>\mathrm{K}>\mathrm{Zn}>\mathrm{Mn}>\mathrm{Mg}>\mathrm{Cu}>\mathrm{Ca}>\mathrm{Fe}$.

$O$ perfil mineral das infusões das plantas medicinais avaliadas sugere que os chás pesquisados podem ser uma fonte de minerais, principalmente $\mathrm{K}$ e Mn. Porém, vale salientar que o conhecimento do melhor tratamento e processamento da planta é indispensável para que estes nutrientes sejam biodisponibilizados.

\section{AGRADECIMENTOS}

Os autores agradecem ao IFMT - Campus Cuiabá - Bela Vista, ao Laboratório de Análises de Contaminantes Inorgânicos do Departamento de Química da UFMT - Campus Cuiabá e a Faculdade de Nutrição da UFMT - Campus Cuiabá pela contribuição na execução dos experimentos do presente trabalho e, ao CNPq pela concessão de bolsa de iniciação científica a F.G.G.P.

\section{REFERÊNCIAS}

AITA, A. M. et al. Espécies medicinais comercializadas como "quebra-pedras" em Porto Alegre, Rio Grande do Sul, Brasil. Revista Brasileira de Farmacognosia, v.19 (2A), n. 2, p. 471-477 2009.

ALMEIDA, M. M. B. et al. Determinação de nutrientes minerais em plantas medicinais. Ciência e Tecnologia de Alimentos, v.22, n.1, p. 94-97, 2002.

ALMEIDA, M. M. B. et al. Determinação de umidade, fibras, lipídios, cinzas e sílica em plantas medicinais. Boletim do Centro de Processamento de Alimentos, v.21, n.2, p.343-350, 2003.

AMARAL, A. S. et al. Cultivo de carqueja (baccharis trimera) em solução nutritiva com diferentes concentrações de nitrogênio, fósforo e potássio. Perspectiva, v.34, n.127, p. 25-34, 2010.

AMARANTE, C. B. et al. Avaliação da composição mineral do chá da folha senescente de Montrichardia linifera (Arruda) Schott (Araceae) por espectrometria de absorção atômica com chama (FAAS), Química Nova, v. 34, n.3, p. 419-423, 2011.

AOAC. Association of Official Analytical Chemists. Official methods of analysis.19a ed. Washington: Editorial Board, 2012, 3000p.

BERTOL, A. et al. Determinação de minerais em algumas plantas medicinais utilizadas em Xanxerê oeste catarinense. Unoesc \& Ciência, v. 6, n. 1, p.53 $-58,2015$.

BORGES, L.R. et al. Determinação de atividades biológicas em extratos de carqueja (Baccharis Trimera (Less) D.C.). In: CONGRESSO DE ECOLOGIA DO BRASIL, 8., 2007, Caxambu. Proceedings...Caxambu:

Rev. Bras. PI. Med., Campinas, v.18, n.1, supl. I, p.297-306, 2016. 
SEB, 2007, p. 1-2.

BRASIL. Ministério da Saúde. Agência Nacional de Vigilância Sanitária. Resolução RDC n³60, de 23 de setembro de 2003. Aprova regulamento técnico sobre rotulagem nutricional de alimentos embalados, tornando obrigatória a rotulagem nutricional. DOU. Diário Oficial da União, Poder Executivo, DF, Brasília, 2003.

BRASIL. Ministério da Saúde. Agência Nacional de Vigilância Sanitária. Resolução RDC n² 269, de 22 de setembro de 2005. Aprova Regulamento técnico sobre a ingestão diária recomendada (IDR) de proteína, vitaminas e minerais. DOU. Diário Oficial da União, Poder Executivo, DF, Brasília, 2005.

BRASIL. Agência Nacional de Vigilância Sanitária. Farmacopéia Brasileira. 5. ed., v. 2. Brasília: ANVISA, 2010. 904 p.

CABRAL, P. R. F.; PASA, M. C. Mangava-brava: lafoensia pacari a. st. - hil. (lythraceae) e a Etnobotânica em Cuiabá, MT. Revista Biodiversidade, v.8, n.1, p. 2-21, 2009.

CARLOS, L. et al. Crescimento e nutrição mineral de mudas de barbatimão sob efeito da omissão de nutrientes. Floresta, v. 43, n. 4, p. 559 - 568, 2013.

CARVALHO, A. M. et al. Teores de hemiceluloses, celulose e lignina em plantas de cobertura com potencial para sistema plantio direto no cerrado. 290. ed. Brasília: Embrapa Cerrado, 2010.15 p.

CURRIE. L.A. Detection and quantification limits: origins and historical overview. Analytica Chimica Acta, v. 391, p. 127 - 134, 1999.

FIORINI, L. S. Dossiê: Os minerais na alimentação. Revista Food Ingredients Brasil, n. 4, p. 48-65, 2008.

FIGUEIREDO, A. P.; PEREIRA, R. S. Estudo dos efeitos de cápsulas de carqueja (Baccharis Trimera (LESS) D.C.), sobre o metabolismo lipídico de pacientes em processo de emagrecimento. Conexão Ciência, v.4, n. 1, p. 15, 2009

FOOD AND NUTRITION BOARD. Dietary Reference Intakes: A Risk Assessment Model for Establishing Upper Intake Levels for Nutrients. 1.ed. Washington: Nacional Academic Press, 1998. $71 \mathrm{p}$.

GARBIN, L. et al. Avaliação da qualidade de plantas medicinais distribuídas por uma unidade de saúde de um município do interior do Paraná. Revista Ciências Exatas e Naturais, v.15, n.1, p. 77-93, 2013.

GOULART, S.L. et al. Análises químicas e densidade da madeira de raiz, fuste e galho de barbatimão [(stryphnodendron adstringens) coville] de bioma cerrado. Cerne, v. 18, n. 1, p. 59-66, 2012.

HUSSAIN, J. et al. Assessment of herbal products and their composite medicinal plants through proximate and micronutrients analyses. Journal of Medicinal Plants Research, v. 3, n.12, p. 1072-1077, 2009.

INSTITUTO ADOLFO LUTZ. Métodos físicosquímicos para análise de alimentos. São Paulo: Instituto Adolfo Lutz, 2008. 1018 p.

KARAM, T.K. et al. Carqueja (Baccharis trimera): utilização terapêutica e biossíntese. Revista Brasileira de Plantas Medicinais,v.15, n. 2, p.280-
286, 2013.

KINUPP, V.F.; BARROS, I.B.I. Teores de proteína e minerais de espécies nativas, potenciais hortaliças e frutas. Revista Ciência e Tecnologia de Alimentos, v.28, n.4, p.846-57, 2008.

KRÓL, J. et al. Content of selected essential and potentially toxic trace elements in milk of cows maintained in eastern Poland. Journal of Elementology, v.17, n.4, p. 597-608, 2012.

LAHIJI, N. et al. Mineral analysis the infusion of black tea samples by atomic absorption spectrometry. In: E3S WEB OF CONFERENCES, 1., 2013, Rome, Proceedings...Rome: E3S Web of conferences, 2013. p. 1-4.

MARBANIANG, D.G. et al. Study of trace metal ( $\mathrm{Cr}$, $\mathrm{Mn}, \mathrm{Fe}, \mathrm{Co}, \mathrm{Ni}, \mathrm{Cu}, \mathrm{Zn}$ and $\mathrm{Cd}$ ) composition in tea available at Shillong, Meghalaya, India. International Journal of Environmental Protection ,, v.1, n.1, p.13-21, 2011.

MARQUES, G. S. et al. Caracterização fitoquímica e físico-química das folhas de Bauhinia forficata Link coletada em duas regiões brasileiras. Revista de Ciências Farmacêuticas Básica e Aplicada, v.33 n.1, p.57-62, 2012.

OLIVIER, J. et al. Comparison of the mineral composition of leaves and infusions of traditional and herbal teas. South African Journal of Science, v.108, n.1, p. 1-7, 2012.

RANDELOVIĆ, S. S. et al. The correlation of metal content in medicinal plants and their water extracts., Hemijska Industrija, v.67, n. 4, p.585-591, 2013.

RIBANI, M. Validação em métodos cromatográficos e eletroforéticos. Química Nova, v. 27, n. 5, p. 771780, 2004.

SANTOS, L.W. et al.. Fenologia de lafoensia pacari A.St.-Hil. (Lythraceae) em Barra do Garças, Mato Grosso, Brasil. Revista Brasileira de Plantas Medicinais, v.11, n.1, p.12-17, 2009.

SIMÃO, A. A. Composição química, eficácia e toxicidade de plantas medicinais utilizadas no tratamento de obesidade. 2013. 182 p. Tese (Doutorado - Área de concentração Agrouímica) Universidade Federal de Lavras, Lavras.

SILVA, B. C.; SILVA, F.; MICHELIN, D. C. Avaliação da qualidade de amostras de Camellia sinensis (L.) Kuntze (Theaceae) comercializadas no município de Araras - SP. Revista de Ciências Farmacêuticas Básica Aplicada, v.34, n. 2, p.245-250, 2013.

SILVA, T. C. L. et al. Acute toxicity study of stonebreaker (Phyllanthus tenellus Roxb.). Revista de Ciências Farmacêuticas Básica Aplicada, v.33, n.2, p.205-210, 2012.

SILVEIRA, L. M. S. et al. Extração de Minerais em Planta de uso Medicinal Através da Infusão e Digestão por Microondas, Revista Brasileira de Farmácia, v.90, n.2, p.144 - 14, 2009.

SKOOG, D. A. Princípios de análise instrumental. 6.ed. São Paulo Editora Bookman, 2009. 1056 p.

TEIXEIRA, F.; MARTINS, M. V. D.M. Barbatimão (Stryphnodendron adstringens (Mart.) Coville): Uma Revisão Bibliográfica de sua Importância Farmacológica e Medicinal. Cenarium Pharmacêutico, v.3, n. 3, p. 1-6, 2009. 
TEIXEIRA, G. S. et al. Plantas Medicinais, Fitoterápicos e/ ou Nutracêuticos Utilizados no Controle da Obesidade. Boletim do Grupo em Pesquisa da Flora, Vegetação e Etnobotânica,, v.1, n. 6, p. 27- 42, 2014.

VICTÓRIO, C. P. et al. Standardized Production of Phyllanthus tenellus Roxb. by Plant Tissue Culture. Revista Ciência Agronômica, v. 41, n. 2, p. 272-278,
2010.

ZHANG, Y. et al. Study on Simultaneous Determination of Potassium, sodium, Phosphosrus, Sulfur, Iron, Manganese, Copper, Zinc, Calcium, Magnesium in Tea Infusion by Inductively Coupled Plasma Atomic Emission Spectrometry. Research Publisher, v. 2, n. 2, p. 41-47, 2014.

Rev. Bras. PI. Med., Campinas, v.18, n.1, supl. I, p.297-306, 2016. 